\title{
Introducing New Members of the Editorial Board of Metallography, Microstructure, and Analysis
}

Editor-in-chief Ryan M. Deacon is pleased to introduce two new members of the Editorial Board of Metallography, Microstructure, and Analysis. The advice, expertise, and support of the Editorial Board contribute greatly to the ongoing success of the journal.

\section{Elizabeth Hoffman}

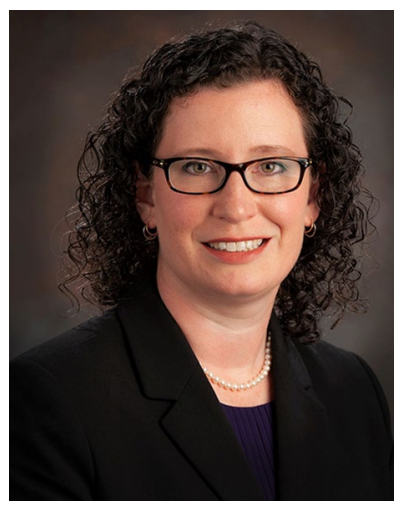

Elizabeth Hoffman is the Director of Innovation and University Engagement at the Savannah River National Laboratory (SRNL), a multi-program national laboratory of the U.S. Department of Energy specializing in environmental remediation, nuclear materials processing, nuclear detection, and materials characterization. Dr. Hoffman is responsible for SRNL's Laboratory Directed Research and Development Program, Postdoctoral Researcher Program, and University Engagement Program. All three programs advance the state of science through collaboration and partnership. Dr. Hoffman received her Ph.D. and B.S. in materials science and engineering in 2006 and 2002, respectively, from Drexel University. Dr. Hoffman has been recognized as a Fellow of ASM International.

\section{Michael R. Kracum}

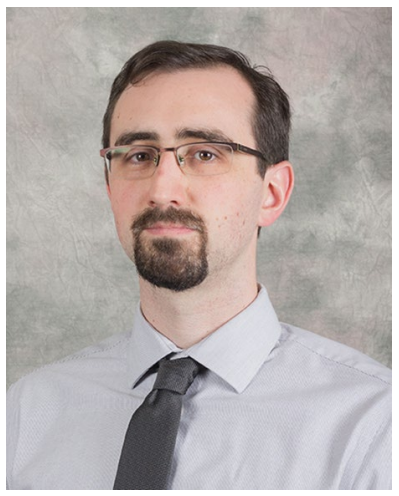

Michael Kracum is a Senior Research Engineer in the Advanced Materials group at United Technologies Research Center in East Hartford, Conn. His research focuses on the development of high temperature ceramics and ceramic composites for aerospace applications at Pratt \& Whitney and Collins Aerospace.

He received his B.S. and Ph.D. from Lehigh University in Bethlehem, Pa. While at Lehigh, Dr. Kracum organized and ran an undergraduate ceramic lab inspired by the annual Mug Drop competition held at MS\&T. He is a member of the Basic Science Division and Engineering Ceramics Division of the American Ceramic Society, and has interests in scientific outreach activities such as the ASM Materials Camp that he organized at Lehigh.

Publisher's Note Springer Nature remains neutral with regard to jurisdictional claims in published maps and institutional affiliations. 